\title{
COMBINED SPINAL-EPIDURAL ANESTHESIA WITH MINIDOSE BUPIVACAINE-FENTANYL FOR HIP SURGERY IN ELDERLY PATIENTS
}

feyzi celik ( $\nabla$ drfeyzicelik@gmail.com )

Dicle Universitesi https://orcid.org/0000-0001-5986-8785

Zeynep Baysal -Yildirim1

Dicle Universitesi

Haktan Karaman

Dicle Universitesi

Abdulmenap Güzel

Dicle Universitesi

Research article

Keywords: Combined spinal epidural anesthesia, hip surgery, mini-dose bupivacaine

Posted Date: February 20th, 2019

DOI: https://doi.org/10.21203/rs.2.353/v1

License: (c) (i) This work is licensed under a Creative Commons Attribution 4.0 International License.

Read Full License 


\section{Abstract}

Background: In this study, the effects of mini-dose isobaric bupivacaine with fentanyl on motor and sensory blockade with combined spinal epidural anesthesia were evaluated in patients $>65$ years undergoing total hip arthroplasty.

Methods: A total of 100 American Society of Anesthesiologists (ASA) class III-IV patients $>65$ years were enrolled. The patients received a combined spinal epidural into the intrathecal catheter space of $5 \mathrm{mg}$ $0.5 \%$ bupivacaine and $10 \mu \mathrm{g}$ fentanyl (total $1.1 \mathrm{ml}$ ). Levels of sensory and motor blockade, hemodynamic parameters, and the resulting complications were recorded.

Results: The mean age of patients (44 females and 56 males) was $79 \pm 5.70$ (range: 70-93) years. Of the 100 patients, 88 were classified as ASA III and 12 as ASA IV. The average duration of surgery was $59 \pm 10$ min. Comorbidities in patients with hip prostheses were examined. Heart rate and mean arterial blood pressure values were stable and similar at all times. The time to reach the T10 level of sensory blockade after spinal anesthesia was $10 \pm 5.03 \mathrm{~min}$. Motor block regression time was $132.06 \pm 14.12 \mathrm{~min}$.

Conclusion: An anesthetic technique was applied considering the physiological changes in elderly hip surgery patients. The $5 \mathrm{mg}$ isobaric bupivacaine and $10 \mu \mathrm{g}$ fentanyl combination provided adequate anesthesia without affecting the hemodynamic parameters.

\section{Background}

The World Health Organization defines 65 years of age as 'older' or 'elderly' and $\geq 80$ years of age as the 'oldest-old.' Many physiological and anatomical changes occur in aging patients, and these patients also have comorbidities [1]. The need for surgical anesthesia has increased in many of the oldest-old patients.

Hip fractures more commonly occur in the oldest-old age group of patients and regional anesthesia methods are preferred due to the presence of concomitant diseases [2-6]. Regional anesthesia is preferred over general anesthesia, as the patient remains conscious, pulmonary function is preserved, no intubation is required, less surgical bleeding is encountered, a decreased risk of thromboembolic complications is observed, and the procedure costs less. Sufficient analgesia can be achieved by administering low-dose local anesthetics via a spinal anesthesia technique. However, this method has disadvantages, such as an irreversible inadequate block, inability to extend anesthesia duration for a prolonged surgery, and the need for other methods to relieve pain during the postoperative period [7-9]. The onset of action is longer with epidural anesthesia. However, the possibility of a toxic reaction is higher, as it requires the use of high-dose local anesthetic drugs. The combined spinal-epidural anesthesia (CSEA) technique was developed to eliminate these disadvantages associated with using spinal or epidural anesthesia alone. Another advantage of CSEA is that it provides postoperative analgesia [10]. 
The most commonly used regional anesthesia method for lower extremity operations in elderly patients is the spinal anesthesia technique [4]. Hypotension is one of the most feared complications of spinal anesthesia. The incidence of coronary artery disease is quite high in elderly patients. Hypotension induced by sympathetic blockade provokes existing ischemic heart disease in this group of patients and requires additional medications. The use of intravenous fluids and vasopressors to prevent spinal anesthesia-induced hypotension is a common practice. Another approach is to reduce the intrathecal local anesthetic agent dose. Opioids are the most frequently used adjuvants to local anesthetic agents [4]. Few studies have been performed on the use of intrathecal low-dose local anesthetics for hip surgery operations in the oldest-old patients. Therefore, we present our recent findings here. We evaluated the effects of mini-dose isobaric bupivacaine with fentanyl on motor and sensory blockade with combined spinal epidural anesthesia in patients $>65$ years undergoing total hip arthroplasty.

\section{Methods}

The records of 103 American Society of Anesthesiologists (ASA) class III-IV group patients $>65$ years of age who underwent total hip replacement surgery under combined spinal-epidural anesthesia between October 2009 and October 2017 were evaluated after obtaining permission of the Ethics Committee of Dicle University, Faculty of Medicine Research Hospital. Three patients were not included in the study due to a failed attempt at CSEA.

Preoperative routine monitoring ( $\mathrm{ECG}, \mathrm{SpO}_{2}$, noninvasive blood pressure) was performed in all patients. The patients were given $5 \mathrm{ml} / \mathrm{kg}$ of a colloid infusion within $20 \mathrm{~min}$ before the intervention. The surgical site was sterilized with povidone-iodine, and local anesthesia was administered with the patient in a sitting position. Regional anesthesia was administered at the L3-4 interspace in all patients. The epidural space was reached by the loss-of-resistance technique using an $18 \mathrm{G}$ Tuohy (Perican $\AA$, B. Braun, Melsungen, Germany) epidural needle. The subarachnoid space was entered with a $27 \mathrm{G}$ Quincke spinal needle (Espocan ${ }^{\circledR}$, B. Braun) inserted through the epidural needle.

After obtaining cerebrospinal fluid flow, $1.1 \mathrm{ml}$ of $5 \mathrm{mg}(1 \mathrm{ml}) 0.5 \%$ isobaric bupivacaine and $10 \mu \mathrm{g}$ fentanyl $(0.1 \mathrm{ml})$ was injected. The epidural catheter was fixed at an epidural distance of 3-4 cm. The level of the sensory block was checked with the pin-prick test. A sensory block level of T10 was targeted for the beginning of the surgical intervention. The degree of motor block was assessed by the Bromage scale (Bromage scale: 0: no paralysis, patient can fully flex foot and knee. 1: Can only move knee and foot, cannot perform straight leg-lift. 2: Cannot bend knee, can only move foot. 3: Full paralysis). Heart rate, systolic and diastolic-mean arterial pressures, $\mathrm{SpO}_{2}$, and the sensory and motor block levels were checked within the first $5 \mathrm{~min}$.

In cases when the initial dose of bupivacaine was insufficient (sensory block level below the T10 dermatome) and pain was present during the operation, $5 \mathrm{ml}$ of bupivacaine $(0.25 \% \mathrm{mg})$ was 
administered epidurally.

Demographic data, concomitant diseases, surgical duration, hemodynamic parameters, additional epidural analgesic requirements, first postoperative analgesic requirement, complications, and patient and surgical satisfaction data were evaluated.

Statistical analysis: The data analysis was carried out using SPSS for Windows 15.0 software (SPSS Inc., Chicago, IL, USA). Descriptive statistics and continuous measurement variables are presented as mean \pm standard deviation, whereas classifiable variables are expressed as number of cases ( $\mathrm{n}$ and \%). Differences between means were assessed by Student's $t$-test. A $p$-value $<0.05$ was considered significant.

\section{Results}

The mean age of patients (44 females and 56 males) included in the study was $79 \pm 5.70$ (range: 70-93) years. Of the 100 patients, 88 were classified as ASA III and 12 as ASA IV patients. The mean duration of surgery was $59 \pm 10 \mathrm{~min}$ (Table 1). Hypertension was the most frequent concomitant condition in the patients who underwent hip arthroplasty (Table 1). Heart rate and mean arterial pressure values measured at all times were similar, and hemodynamic parameters remained stable (Fig. 1). No decrease in the $\mathrm{SpO}_{2}$ value was detected during the perioperative period, and oxygen was delivered to the patients through a mask.

The time until the sensory block reached the T10 level after spinal anesthesia was $10 \pm 5.03 \mathrm{~min}$ and the time of starting the operation was $11.3 \pm 2.3 \mathrm{~min}$. Patients were administered $5 \mathrm{ml} / \mathrm{kg}$ colloid before the operation and $4 \mathrm{mg} / \mathrm{kg} /$ hour crystalloid fluid infusion during the operation; $5 \mathrm{mg}$ of intravenous ephedrine was used in only three patients. Table 3 lists the times of the first analgesic requirement after the operation and any complications that occurred. Motor block regression time was $132.06 \pm 14.12 \mathrm{~min}$. A single dose of $3 \mathrm{mg} / 10 \mathrm{ml}$ morphine was administered postoperatively through the epidural catheter as an analgesic in patients with a visual analogue scale (VAS) score $\geq 5$. Patient satisfaction for the general course of the procedure was sufficient.

\section{Discussion}

More patients are being offered major elective and emergency surgery services with aging [11]. However, there is an increased risk of surgical mortality in these patients due to comorbidities [12]. Mean age and the ASA class of the patients was high in our study (Table 1).

The method of anesthesia, physiological changes in the elderly, concomitant diseases and drugs used in the treatment of these diseases, the type of surgery, and postoperative pain treatment affect mortality and morbidity rates. Despite developments in general anesthesia, regional anesthesia techniques are 
widely used in both surgery and pain treatment. Regional anesthesia has fewer negative effects on endocrine metabolic responses during surgery and vital signs compared to general anesthesia. Other reasons for the popularity of regional anesthesia include less blood loss, decreased risks of thromboembolism and cardiac and respiratory complications, rapid recovery of postoperative gastrointestinal functions, and the provision of superior postoperative analgesia [6, 8]. Theoretical interpretations, clinical results, and personal choices suggest that regional anesthesia is safer than general anesthesia in the geriatric population undergoing surgery [13]. Because of these advantages, we prefer to use regional anesthesia with the CSEA method in our patients.

Older patients undergoing hip surgery are at a high risk of cardiac complications [14]. Michael et al. [15] found that most intraoperative mortality in patients undergoing primary total hip arthroplasty is related to cardiovascular pathology. The frequency of complications occurring during general anesthesia in older patients with comorbid diseases undergoing lower extremity orthopedic surgery makes regional anesthesia the preferred method in this group of patients. The most commonly used regional anesthesia method is single-dose spinal anesthesia. However, single-dose spinal anesthesia has a limited duration of action and additional medication cannot be administered in cases where the level of the block remains low, so this poses a problem in terms of perioperative analgesia $[2,3]$.

The CSEA technique is frequently used in this age group of patients. The use of intrathecal low-dose local anesthetics, the ability to provide epidural local anesthetic support in cases where the block level is insufficient, and effective analgesia during the postoperative period allows early mobilization of patients [16]. CSEA is often preferred in elderly patients undergoing hip replacement surgery in our clinic because most of these patients have hypertension, heart failure, diabetes mellitus, and chronic obstructive pulmonary disease (COPD). Limiting the block level in these patients reduces cardiopulmonary side effects and allows for rapid recovery [17]. Hypertension and COPD were the most common comorbidities in our study (Table 2).

The capacity of the autonomic nervous system and blood vessels to provide hemodynamic stability decreases with advanced age due to reduced parasympathetic activity, atherosclerosis, increased systemic vascular resistance, and left ventricular hypertrophy [18]. The progression of fibrosis with age decreases the reservoir function of the venous system against changes in volume, and hypotension can become more severe [19].

O'Hara et al. [20] reported an increased incidence of hypotension in a regional anesthesia group. Spinal anesthesia may cause hypotension due to blood pooling in lower extremities and the splanchnic area as a result of vasodilation caused by the sympathetic blockade [21]. Patients in the oldest-old age group are more affected by the hemodynamic instability caused by a spinal block [22]. The risk of ischemic heart disease secondary to hypotension is high in this population. There has been much discussion about the use of vasopressors and intravenous fluids to prevent this condition [4]. Methods such as the use of local anesthesia at the lowest possible dose, adding an opioid to low-dose local anesthesia, or unilateral block, are used in elderly patients to avoid hemodynamic instability [23]. 
A low-dose local anesthetic reduces the incidence of hypotension by inducing less sympathetic block. Additionally, its use allows the motor and sensory blocks to recover more quickly [17]. Isobaric bupivacaine at $<10 \mathrm{mg} / \mathrm{kg}$ has been recommended to reduce the risk of hypotension in elderly patients. However, a spinal block with a low-dose local anesthetic agent may not always provide an adequate level of anesthesia. Therefore, it has been recommended to add an opioid [24]. Adding a lipophilic opioid to a local anesthetic for spinal anesthesia increases the quality of the anesthesia without prolonging the duration of the motor block. It also allows the motor block to recover more quickly [24]. Because opioids have a synergistic effect with local anesthetics without causing a sympathetic block, adding an opioid to spinal anesthesia reduces the required local anesthetic dose, provides a more stable blood pressure, and improves the quality of anesthesia [17].

In a previous study, the lowest local anesthetic dose administered to patients undergoing hip surgery was $4 \mathrm{mg}$ bupivacaine combined with $20 \mu \mathrm{g}$ fentanyl in 10 patients. While this dose provided adequate anesthesia, it led to a minimum level of hypotension and the need for vasopressors [24]. Some studies have shown that the CSEA method produces dramatically less severe hypotension than spinal anesthesia [25]. In our clinic, the CSEA technique is preferred in elderly patients undergoing hip replacement surgery. In this study, we analyzed the results of a series of 100 patients who were administered anesthesia with this technique. Using the CSEA technique, patients were administered $5 \mathrm{mg}$ of bupivacaine and $10 \mu \mathrm{g}$ of fentanyl ( $1.1 \mathrm{~mL}$ of drug in total) intrathecally, and surgery was initiated. Sufficient anesthesia was achieved with this dose, and only three patients developed hypotension. We believe that this was due to addition of the opioid to the low-dose local anesthetic that we used.

During surgery, six patients were administered an additional $5 \mathrm{ml}$ of $0.25 \%$ bupivacaine through the epidural catheter due to inadequate anesthesia. We found that the time taken for the sensory block to reach the T10 level was $10 \pm 5.03$ min by the pin-prick test, and this result is consistent with previous studies. Because of the patients' age and limited lung capacity, fluid replacement was performed with 6 $\mathrm{mL} / \mathrm{kg}$ colloid preoperatively and with $4 \mathrm{~mL} / \mathrm{kg} /$ hour crystalloid solution intraoperatively, considering that excessive fluid loading could lead to pulmonary edema.

Early recovery of motor block is effective for preventing complications, such as thromboembolic events and lung complications that may develop during the postoperative period, particularly in the geriatric patient population. Motor block regression time was $132.06 \pm 14.12 \mathrm{~min}$, which was shorter than other studies [26, 27].

Postoperative pain management is important in these patients. The first 24-48 postoperative hours are important for effective pain control in patients with coronary artery disease, so a close follow-up is recommended. In our study, the CSEA technique was applied, and $3 \mathrm{mg} / 10 \mathrm{ml}$ of morphine was administered through the epidural catheter when the VAS score was $\geq 5$ to prevent postoperative pain.

\section{Study limitations}

Main limitation of this study is its retrospective nature and single centre experience. 


\section{Conclusions}

Adequate anesthesia can be achieved in elderly patients undergoing hip surgery with $5 \mathrm{mg}$ isobaric bupivacaine and $10 \mu \mathrm{g}$ fentanyl without affecting hemodynamic parameters when the appropriate anesthesia technique is used, physiological changes are considered, and the appropriate drug and dose are selected.

\section{Abbreviations}

ASA: American Society of Anesthesiologists

ml: milliliter

CSEA: combined spinal-epidural anesthesia

ECG: electrocardiography

$\mathrm{SpO}_{2}$ : peripheral oxygen saturation

G: gauge

T: Thoracic vertebra

VAS: visual analogue scale

COPD: chronic obstructive pulmonary disease

M, Male

F, Female

$\min : \min$

\section{Declarations}

\section{Acknowledgments}

The authors would like to thank the Department of Anesthesia and Department of orthopedics and traumatology, Faculty of Medicine, Dicle University, Turkey, for their participation

\section{Funding}

The authors declared that this study did not receive any funding.

\section{Availability of data and materials}


The data used to support the findings of this study are available from the corresponding author upon request. These data are not publicly available due to patient confidentiality.

\section{Authors' Contributions}

FC: collected, analysed and interpreted data, wrote the manuscript. ZBY: collected and analysed data. HK: collected, analysed and interpreted data, wrote the manuscript. AG: analysed and interpreted data, critical revision of the manuscript. All authors read and approved the manuscript. All authors contributed this work.

\section{Ethics approval and consent to participate}

Due to the retrospective nature of the data, approval from the local ethics committee was required. Furthermore, no data can be traced to any individual. (dicle university medical faculty ethics committee. number:155).

\section{Consent for publication}

Not applicable

\section{Competing interests}

The authors declare that they have no conflict of interests.

\section{References}

[1]. Kanonidou Z, Karystianou G. Anesthesia for the elderly. Hippokratia 2007;11:175-7.

[2]. Valentin N, Lomholt B, Jensen JS, Hejgaard N, Kreiner S. Spinal or general anaesthesia for surgery of the fractured hip. Br J Anaesth 1986;58:284-91.

[3]. Dahl V, Gierløff C, Omland E, Raeder JC. Spinal, epidural or propofol anaesthesia for outpatient knee arhroscopy. Acta Anaesthesiol Scand 1997;41:1341-5.

[4]. Ben-David B, Frankel R, Arzumonov T, Marchevsky Y, Volpin G. Minidose Bupivacaine-Fentanyl Spinal Anesthesia for Surgical Repair of Hip Fracture in the Aged. Anesthesiology 2000;92:6-10.

[5]. Beaupre LA, Jones CA, Saunders LD, Johnston DW, Buckingham J, Majumdar SR. Best practices for elderly hip fracture patients. A systematic overview of the evidence. J Gen Intern Med 2005; 20:10191025. http://dx.doi.org/10.1111/j.1525-1497.2005.00219.x PMid:16307627 PMCid:1490246

[6]. Levine WC, Mehta V, Landesberg G. Anesthesia for the elderly: selected topics. Curr Opin Anaesthesiol 2006; 19:320-324. http://dx.doi.org/10.1097/01.aco.0000192807.63785.59 PMid:16735817

[7]. Erdine S. Sinir Blokları. 1. Baskı. İstanbul: Emre Matbaacılık 1993, 49-80, 155-210, 221-230. 
[8]. Kayhan Z. Klinik Anestezi. 2. Baskı. Logos Yayıncllık 1997, 435-453, 477-503.

[9]. Collins VJ. Principles of Anesthesiology 3rd. Edition Volum I-II Lea and Febiger Philadelphia 1993, 12$63,708-709,1259-1262,1445-1571$.

[10]. Yücel A. Kombine Spinal Epidural Anestezi Uygulamaları. In: Erdine S, editor. Rejyonel anestezi. 2 Baskı. İstanbul: Nobel Tıp Kitapevleri. 2008. p 187-189

[11]. Türkmen A, Turgut N. Geriatrik Anestezi. Turkish Journal of Geriatrics 2007;10:49-56

[12]. Karslı B, Kafalı ï, Mimaroğlu C, Özok U. Geriatrik Anestezi. T Klin Tıp Bilimleri 1994;14:309-13.

[13]. Hepaguslar H, Elar Z. Geriyatrik olgularda genel veya rejyonel anestezi seçimi. Türkiye Klinikleri Anestezi ve Reanim 2003;1:41-5.

[14]. Salerno SM, Carlson DW, Soh EK, Lettieri CJ. Impact of perioperative cardiac assessment guidelines on management of orthopedic surgery patients. Am J Med Feb 2007;120:185-6.

[15]. Aynardi M, Pulido L, Parvizi J, Sharkey PF, Rothman RH. Early mortality after modern total hip arthroplasty. Clin Orthop Relat Res 2009;467: 213-8.

[16]. Möllmann M, Cord S, Holst D, Auf der Landwehr U. Continuous spinal anaesthesia or continuous epidural anaesthesia for post-operative pain control after hip replacement?. Eur J Anaesthesiol 1999;16:454-61.

[17]. Kim SY, Cho JE, Hong JY, Koo BN, Kim JM, Kil HK. Comparison of intrathecal fentanyl and sufentanil in low-dose dilute bupivacaine spinal anaesthesia for transurethral prostatectomy. British Journal of Anaesthesia 2009;103:750-4.

[18]. Rooke GA, Robinson BJ. Cardiovascular and autonomic nervous system aging. Problems in Anesthesia 1997;9:482-97.

[19]. Sielenkammper A, Booke M. Anaesthesia and the Elderly. Current Opinion in Anaesthesiology 2001;14:679-84.

[20]. O'Hara DA, Duff A, Berlin JA. The effect of anesthetic technique on postoperative outcomes in hip fracture. Anesthesiology 2000; 92:947-957. http://dx.doi.org/10.1097/00000542-200004000-00011 PMid: 10754613

[21]. Liu SS, McDonald SB. Current issues in spinal anesthesia. Anesthesiology 2001;94:888-906.

[22]. Oğurlu M, Şen S, Uğur B, Dişcigil G, Aydın On, Gürsoy F. 65 Yaş Üstü Hastalarda Spinal Anesteziye Bağlı Hipotansiyon Gelişiminin Değerlendirilmesi. Turkish Journal of Geriatrics 2006;9:126-9. 
[23]. Martyr JW, Clark MX. Hypotension in elderly patients undergoing spinal anaesthesia for repair of fractured neck of femur. A comparison of two different spinal solutions. Anaesth Intensive Care 2001;29:501-5.

[24]. Ben-David B, DeMeo PJ, Lucyk C, Solosko D. Minidose lidocaine-fentanyl spinal anesthesia in ambulatory surgery: prophylactic nalbuphine versus nalbuphine plus droperidol. Anesth Analg 2002;95:1596-600.

[25]. Minville V, Fourcade O, Grousset D, Chassery C, Nguyen L, Asehnoune K, et al. Spinal Anesthesia Using Single Injection Small-Dose Bupivacaine Versus Continuous Catheter Injection Techniques for Surgical Repair of Hip Fracture in Elderly Patients. Anesth Analg 2006;102:1559-63.

[26]. Fattorini F, Ricci Z, Rocco A, Romano R, Pascarella MA, Pinto G. Levobupivacaine versus racemic Bupivacaine forspinal anaesthesia in orthopaedic major surgery. Minerva Anestesiol 2006;72:637-44.

[27]. Siddik-Sayyid SM, Aouad MT, Jalbout MI, Zalaket MI, Berzina CE, Baraka AS. Intrathecal versus intravenous fentanyl for supplementation of subarachnoid block during cesarean delivery. Anesth Analg 2002;95:209-13.

\section{Tables}

Table 1. Orthopedic surgery patient characteristics

\begin{tabular}{lc}
\hline Age $(\mathrm{yr})$ & $79 \pm 5.70$ \\
Height $(\mathrm{cm})$ & $165 \pm 8.4$ \\
Weight $(\mathrm{kg})$ & $64 \pm 11.3$ \\
Sex (M/F) & $56 / 44$ \\
ASA III/IV & $88 \pm 12$ \\
Surgical time (min) & $59 \pm 10$ \\
\hline
\end{tabular}

The results were presented as mean \pm standard deviation.

M, Male; F, Female min: $\min$

ASA, American Society of Anesthesiologists.

Table 2. Additional diseases. 


\begin{tabular}{lcc}
\hline Additional disease & $\mathrm{n}$ & $\%$ \\
\hline Hypertension (HT) & 18 & 18 \\
Heart failure (HF) & 4 & 4 \\
CHRONIC OBSTRUCTIVE PULMONARY DISEASE (COPD) & 8 & 8 \\
DİABETES MELLİTUS (DM) & 4 & 4 \\
Parkinson's & 2 & 2 \\
HT +DM & 2 & 2 \\
HT +HF & 10 & 10 \\
HT+ COPD & 12 & 12 \\
HT + CRF (CHRONIC RENAL) FAILURE & 2 & 2 \\
HF+COPD & 6 & 6 \\
HF+LUNG CANCER & 2 & 2 \\
DM+ CRF & 2 & 2 \\
DM+ COPD & 1 & 1 \\
HF +COPD+ DM+ HT & 11 & 11 \\
Without any additional disease & 18 & 18 \\
\hline
\end{tabular}

Table 3. Spinal anesthesia characteristics

\begin{tabular}{lc}
\hline Additional analgesic requirements (n/\%) & $10 / 10$ \\
Time to first postoperative analgesic request (min) & 420 \\
Hypotension / bradycardia & $3 / 0$ \\
Nausea/vomiting / Itching / Shivering & $0 / 0 / 0 / 0$
\end{tabular}

\section{Figures}




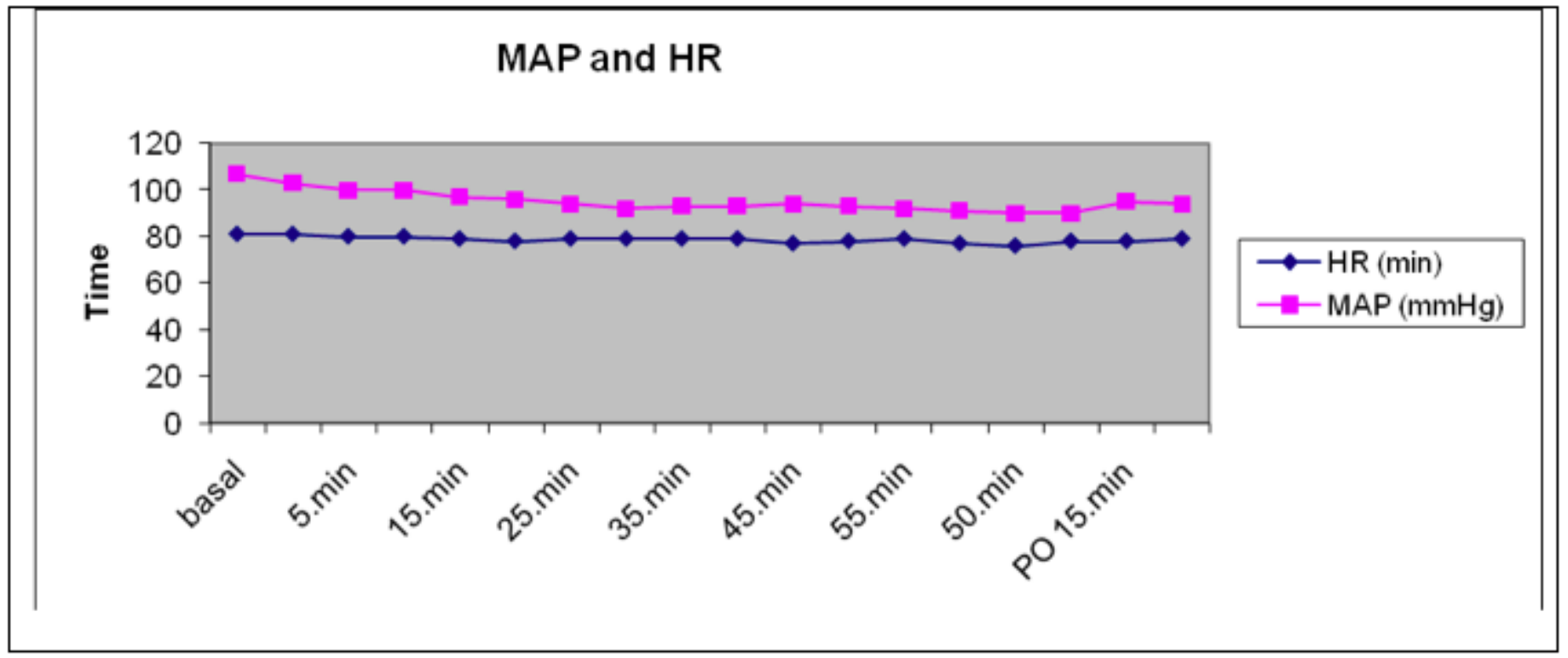

MAP: mean arterial presssure

HR: heart rate

min: minute

Figure 1

MAP and HR during preoperative period in patients. 